\title{
An evaluation of the spatiotemporal structure of large-scale European drought within the HiGEM climate model
}

Article

Accepted Version

Lloyd-Hughes, B., Shaffrey, L. C., Vidale, P. L. and Arnell, N. W. (2013) An evaluation of the spatiotemporal structure of large-scale European drought within the HiGEM climate model. International Journal of Climatology, 33 (8). pp. 2024-2035. ISSN 0899-8418 doi: https://doi.org/10.1002/joc.3570 Available at https://centaur.reading.ac.uk/31133/

It is advisable to refer to the publisher's version if you intend to cite from the work. See Guidance on citing.

Published version at: http://dx.doi.org/10.1002/joc.3570

To link to this article DOI: http://dx.doi.org/10.1002/joc.3570

Publisher: John Wiley \& Sons

All outputs in CentAUR are protected by Intellectual Property Rights law, including copyright law. Copyright and IPR is retained by the creators or other copyright holders. Terms and conditions for use of this material are defined in the End User Agreement.

www.reading.ac.uk/centaur 
Central Archive at the University of Reading

Reading's research outputs online 


\title{
An evaluation of the spatio-temporal structure of large-scale European drought within the HiGEM climate model
}

\author{
Benjamin Lloyd-Hughes ${ }^{a}$, Leonard C. Shaffrey ${ }^{a, b}$, \\ Pier Luigi Vidale ${ }^{b, c}$ and Nigel W. Arnell ${ }^{a}$
}

${ }^{a}$ Walker Institute for climate system research, Department of Meteorology,

University of Reading, UK, ${ }^{b}$ National Centre for Atmospheric Science,

Department of Meteorology, University of Reading, UK, and ${ }^{c}$ UK-Japan Climate Collaboration, Earth Simulator Centre, Yokohama, Japan

Submitted to the International Journal of Climatology

October 28, 2010

Revision 1

May 15, 2012

Corresponding author address: Benjamin Lloyd-Hughes, Walker Institute for climate system research, Department of Meteorology, University of Reading, RG6 6AR, UK. Email: b.lloydhughes@reading.ac.uk 


\section{Abstract}

We compare the characteristics of synthetic European droughts generated by the HiGEM $^{1}$ coupled climate model run with present day atmospheric composition with observed drought events extracted from the CRU TS3 data set. The results demonstrate consistency in both the rate of drought occurrence and the spatio-temporal structure of the events. Estimates of the probability density functions for event area, duration and severity are shown to be similar with confidence $>90 \%$. Encouragingly, HiGEM $^{1}$ is shown to replicate the extreme tails of the observed distributions and thus the most damaging European drought events. The soil moisture state is shown to play an important role in drought development. Once a large-scale drought has been initiated it is found to be $50 \%$ more likely to continue if the local soil moisture is below the $40^{\text {th }}$ percentile. In response to increased concentrations of atmospheric $\mathrm{CO}_{2}$, the modelled droughts are found to increase in duration, area and severity. The drought response can be largely attributed to temperature driven changes in relative humidity.

${ }^{1}$ HiGEM is based on the latest climate configuration of the Met Office Hadley Centre Unified Model (HadGEM1) with the horizontal resolution increased to 1.25 x 0.83 degrees in longitude and latitude in the atmosphere and $1 / 3 \times 1 / 3$ degrees in the ocean.

Keywords: Drought, soil moisture, climate model, climate change, SPI, HiGEM 


\section{Introduction}

Drought is amongst the most deadly of natural hazards. Systematic collection of data relating to natural disasters began around 1970 (Guha-Sapir et al. 2004) and since then recorded droughts have affected the lives of nearly 2 billion people and killed over 600,000. Modern water supply infrastructure can eliminate direct mortalities yet the societal impacts of water scarcity remain and cannot be overstated. For example, the European Commission (EC 2007) estimate the direct costs of drought within the European Union to be $€ 3$ billion per year. This compares annual losses in Europe from windstorms (€2 billion per year) and flooding (€4 billion per year) at 2009 prices. A thorough understanding of the peril is essential for mitigating against the risk as it stands and for preparedness in the face of climate change. A prerequisite for confidence in predictions of the nature of droughts under future climates is that climate models can reproduce droughts characteristic of the present climate. In this paper we compare the nature of the droughts generated by the UK's new high resolution global coupled model with reality. The model, HiGEM (Shaffrey et al. 2009), is based on the latest climate configuration of the Met Office Unified Model, HadGEM1 (Martin et al. 2006). The horizontal resolution has been increased to 1.25 x 0.83 degrees in longitude and latitude for the atmosphere, and $1 / 3 \times 1 / 3$ degrees globally for the ocean. Most notably, HiGEM is process-resolving in the atmosphere and produces realistic teleconnections (Shaffrey et al. 2009, Catto et al. 2010). The analysis of drought within the context of a climate model poses some interesting problems which stem from the inherently nebulous concept of drought itself. The typical pathway for climate model evaluation is to run the model under boundary conditions representative of the recent past and to reduce the model output to a set of index values and/or static maps that can be compared with the historical record (see e.g. Shaffrey et al. (2009) for such an evaluation of HiGEM). It has long been recognised that the study of drought is not amenable to such an approach (for a review see Heim (2002)). Drought occurrence depends on the interaction between

the source of the available water and its intended use. This leads to different perceptions of the importance of a given drought for different segments of society. The 
meteorologist, who views drought as below normal precipitation in a region, might consider a run of 10 dry days to be significant. The arable farmer, who depends on adequate soil moisture for crops during the growing season, will be interested in monthly rainfall totals. Whereas, the water supply company may be interested in aquifer levels that take months or even years to recharge. Location also matters e.g. consider the impact of a summer dry spell of 30 days over London to the same over Tripoli, as does spatial extent. Recognising the intrinsically spatio-temporal nature of drought impacts Lloyd-Hughes (2012) suggests that the space-time structure of the precipitation deficits are better suited to the characterisation the phenomenon. This feature based approach is amenable to the evaluation of the quality of modelled droughts and is applied for the first time here. Whilst the rich information content of the output from this method is not well suited for the purposes of multi-model intercomparisons nor ensemble based estimates of uncertainty, it does provide a robust assessment of a HiGEM's ability to replicate the physical features of drought relevant to real world impact studies. Suitably validated, HiGEM will provide a unique platform for the synthesis of drought data sets of sufficient duration and fidelity for the meaningful study extreme events.

\section{Methodology}

\section{$2.1 \quad$ Data}

We analyse two sets of HIGEM 1.1 model output which were run at the Earth Simulator in Japan as part of the UK Japan Climate Collaboration (UJCC). The first set is comprised of data from a control experiment (100 years post spin-up) in which the model was forced with fixed present-day concentrations of trace greenhouse gases (the concentrations of $\mathrm{CO}_{2}, \mathrm{CH}_{4}, \mathrm{~N}_{2} \mathrm{O}$ being $345 \mathrm{ppm}, 1656 \mathrm{ppb}$ and 307 ppb respectively). The second set is taken from a rapid climate change experiment (eafee) in which the concentration of $\mathrm{CO}_{2}$ was initially increased at a rate of $2 \%$ per year then stabilised, after year 70, at 4 times the present day value. These data were partitioned into two subsets of 30 years each based up the final state of the global mean temperature at the end of a 30 year window. The subsets were chosen to be 
representative of climates $2^{\circ} \mathrm{C}$ and $4^{\circ} \mathrm{C}$ warmer than the present day (1971-2000) these corresponding to model years 2030-2059 and 2061-2090 respectively.

The European domain under study is defined as $15^{\circ} \mathrm{W}$ to $35^{\circ} \mathrm{E}$ and $35^{\circ} \mathrm{N}$ to $70^{\circ} \mathrm{N}$. The model data are compared with observations derived from the CRU TS3 $0.5^{\circ}$ gridded monthly data set restricted to 1971-2000 (Mitchell \& Jones 2005). The highly localised nature of precipitation means that care must be taken when moving between different grids. Here we use conservative interpolation (Jones 1998) to aggregate the CRU data onto the HiGEM grid. Since the CRU data are limited to the land surface, the inverse of the re-gridded CRU land points were used to mask the input HiGEM data. The HiGEM model employs a fractional land mask to differentiate between land and sea. To strictly limit the analysis to the land surface the re-gridded CRU and masked HiGEM data were further masked for any grid points where the land/sea fraction was below 0.5 .

\subsection{Drought definition}

The term 'drought' is frequently used to refer to the adverse impacts of the lack of precipitation rather than the lack of precipitation as a meteorological event (Smakhtin \& Schipper 2008) and this can present difficulties with respect to event definition. In this paper, drought is defined in a strictly meteorological sense. Specifically, it is defined by negative values of the Standardized Precipitation Index (SPI) (McKee et al. 1995) at the 3-monthly time scale $\left(\mathrm{SPI}_{3}\right)$. This definition represents a good proxy for large scale stream flow drought in Europe (Lloyd-Hughes et al. 2009, Szalai \& Szinell 2000) but since an objective definition of drought remains elusive it should be remembered that other definitions may be more appropriate for other applications.

The observational data were standardised relative to the observed climatological totals using the full record 1971-2000. Similarly, the model control data were standardised relative to the model climatology as estimated from the full 100 years. Precipitation from the climate change run were standardised relative to the model control climatology. 


\section{$2.3 \quad$ Feature extraction}

The majority of notable high precipitation events are characterised by highly localised, short lived, heavy down bursts. The same is not true of the most notable drought events. These typically last for several months or even years and span thousands of square kilometres. Thus, drought characterisation is an intrinsically spatio-temporal problem. Following Lloyd-Hughes (2012) we employ an explicit 3-dimensional (longitude, latitude, time) structure based method in which drought events are defined by a spatially and temporarily coherent set of grid cells displaying standardized precipitation below a given threshold. The method extracts coherent space-time structures from within the data. This is achieved by defining drought at a cell if the $\mathrm{SPI}_{3}$ value is $\leq-1$ (below one standard deviation below expected for the 3 monthly period at that time of year at that location). The next step is to locate any neighbouring cells that are also in drought. The definition of neighbour presents several possibilities. At a simple level, neighbouring cells in two dimensions are taken to be those which share a common vertex. However, if the data contain gaps, as is the case here which excludes grid cells over water, then it is useful to extend this concept to cells that share a common vertex at some radius $R$ cells away. Coherency in three dimensions follows similarly by the consideration of common vertices within the data stack in the planes of cells above and below the cell of interest.

It is important to note that this treatment of the data implicitly equates the length scales ( longitude $\equiv$ latitude $\equiv$ time) of the individual cubes (voxels) of data that comprise the drought to be extracted. The general case requires a separate scaling for each dimension (longitude, latitude, time) with radii $\left(R_{\text {lon }}, R_{\text {lat }}, R_{\text {time }}\right)$. Here the grid resolution is relatively coarse and it is sufficient to consider $R_{\text {lon }}$ and $R_{\text {lat }}$ to be comparable and set them equal to one (i.e. we allow spatial gaps of one grid cell in any direction). The explicit time averaging applied in the construction of the SPI provides direct control over the temporal scaling and it is appropriate to set $R_{\text {time }}=0$ and only consider immediate neighbours in time. A detailed analysis of this method as applied to observed European droughts (Lloyd-Hughes 2012) did not reveal any great sensitivity to the choice of these parameters. 
The focus of this analysis is on large scale events and thus the raw $\mathrm{SPI}_{3}$ data are filtered to eliminate spatially coherent events smaller than $500,000 \mathrm{~km}^{2}$. Such an area is of the order typical of the extra-tropical cyclones that dominate the European climate (Barry \& Chorley 2003) and is in agreement with the practice advocated by Sheffield et al. (2009) for eliminating tenuous spatial connections between large-scale drought events. In order to further focus on the most temporally coherent events, the constraint is extended to the degree of spatial overlap between successive time slices of each particular event. Event structures in which the overlap falls below $500,000 \mathrm{~km}^{2}$ are considered to be incoherent and are split into separate events.

\subsection{Summary statistics}

The 3-dimensional nature of the event definition motivates the computation of summary statistics which relate to the event geometry. Measures considered here are the volume, duration, and maximum area. The event volume is particularly useful since this represents a measure of the absolute severity in combined terms of extent and duration. Additionally, the geographic centroids of the events are used to explore the distribution of droughts in space.

\section{Results and discussion}

\subsection{European drought in the present day climate}

Summary statistics representative of structural elements of the extracted drought events are shown in Figure 1 for the HiGEM control run (black) and CRU observations (red). Panel (a) shows the probability density and (b) the cumulative probability for events of a particular volume (severity). Panels (c) to (f) show similar for event duration and maximum areal extent respectively. The shading shown in the cumulative plots represents the $90 \%$ interval estimated from 10,000 bootstrapped replicates of each curve. These show excellent agreement in event volume (severity), duration and maximum areal extent. In each case the samples of model control versus CRU TS3 are statistically indistinguishable. It is particularly reassuring 
that we see excellent agreement in the extreme right hand tails of the distributions. This indicates that HiGEM is correctly synthesising the most extreme, most serious, drought events.

The geographic centroids of the drought events provide useful information about the distribution of events in space. Figure 2 shows a map of these for the control run (black) and CRU TS3 (grey). These too are found to be excellent agreement. Beyond visual inspection, similarity between the spatial distributions of the event centres was formally tested by construction of a 2-dimensional KS-test following the method of Peakcock (1983) this returned a $p$-value $>>0.05$. A final summary statistic of interest is the event rate. From the model control run we extracted 71 events from 100 years which, whilst on the low side, is comparable to the 26 events from 30 years extracted from the observations. Assuming independence between events, which is unlikely to be strictly true (see Section 3.2 below), and modelling drought occurrence as a Bernoulli trial, the $95 \%$ confidence intervals about the measured rates overlap comfortably (model: 0.61 to 0.80 ; observations: 0.69 to 0.96 ).

In common with many climate models HiGEM struggles to replicate the climatologically observed geographical distribution of seasonal precipitation totals. Raw averages for both CRU and HiGEM for summer (JJA) and winter (DJF) are shown in Figure 3. Figure 4 expands upon these and presents a grid cell by grid cell comparison of the statistical distributions of seasonal precipitation from the HiGEM control run with CRU observations. Panels (a) and (b) show the significance of the dissimilarity between the distributions as measured by the Kolmogorov-Smirnov (KS) test for summer and winter respectively. This measures the maximum vertical difference $(D)$ between the empirical cumulative distributions at each location. The significance ( $p$-value) of the test is the probability of obtaining a value of $D$ as large as the one measured given that the null hypothesis is true (that the distributions really are the same). The extremely low $p$-values seen across much of Europe, for both seasons, imply a very low probability of obtaining such a high value of $D$ by chance and we can be confident that the distributions are indeed very different. The origin of the differences is explored through consideration of the basic shapes of the distributions. Figures $4(\mathrm{c})$ to (f) display percentage errors with respect to CRU 
TS3 by season for modelled median precipitation and modelled inter-quartile range respectively. Cells failing the KS-test with a $p$-value $<0.05$ are marked with a cross.

The bulk of the distributional inadequacy of the model data can be traced to bias in the median precipitation (likewise the mean, not shown). In the summer there is a tendency for the model to be too dry across much of central and eastern Europe and too wet toward the north and south. This tendency is reversed in the winter. In general, a similar pattern of discrepancy follows in the spread of the distributions, this being too large when the model displays a wet bias and vice versa. The wintertime errors are consistent with the known tendency for HiGEM to exhibit an anomalous eastern extension of the Atlantic storm track into the centre of Europe (Shaffrey et al. 2009).

We have seen that the raw seasonal precipitation totals from the HiGEM model show significant errors (see Figures 3 and 4) in both location (median) and scale (inter-quartile range). However, after the application of suitable transformations, the model yields realistic looking droughts. This result is not as surprising as it may seem since the construction of the SPI is in effect a quantile based calibration procedure. Such procedures are commonly applied to correct for model biases with seasonal forecast models (see e.g. Wood et al. (2002)). Furthermore, the method used here to identify drought events (spatio-temporal agglomeration) by design selects only the largest, longest lasting, most coherent examples. This can be thought of as a low-pass spatio-temporal filter. Thus, the droughts under examination can be expected to be largely free from the effects of local model biases that degrade the grid point assessment of the model precipitation presented in Figure 4.

The physical origin of large-scale European drought events is an interesting open question. Lloyd-Hughes (2012) considering only observational data, hypothesised that the largest volume events might form as aggregations of smaller $\left(\sim 10^{6} \mathrm{~km}^{2}\right.$, $\sim 3$ month duration) events. The occurrence of these appears to be non-random (it is rare to see more than one small scale event to occur at a time even though geographic constraints freely permit it). This indicates that there maybe physical constraints, governed by the atmospheric circulation, that restrict the development of drought centres. One such mechanism might be a prolonged shift in the storm track (see e.g. 
Blackburn et al. (2008)) that would divert moisture from one region to another but would not allow them to be both deprived of moisture at the same time. Examination of the larger modelled events suggest that, in common with the observations, these may also be formed from the aggregation of several smaller events. Figure 5 shows a large scale drought extracted from the control run which illustrates the case. In a loose sense, it seems that drought encourages the development of more drought. This view is consistent with previous studies which have linked reductions in soil moisture with suppressed precipitation (see e.g. Betts et al. (1996), Schär et al. (1999), Pal \& Eltahir (2003), Ferranti \& Viterbo (2006), Fischer et al. (2007)) and confirms the importance of proper soil moisture initialisation in the production of skilful seasonal forecasts (Fennessy \& Shukla 1999, Kanamitsu et al. 2003).

\subsection{Influence of soil moisture}

A major advantage of model data over observations is the availability of consistent fields of variables such as soil moisture that are typically unavailable from the observational record. This allows us to test the likelihood of a particular small scale drought continuing contingent on the level of soil moisture. For each model drought event extracted from the control run we extracted the soil moisture level beneath its footprint at time three months. This was compared against the climatological value for that month of the year. In Figure 6 (a) we plot drought lifetimes by the soil moisture quantile at three months. Whilst far from linear, there is a clear tendency for the droughts that have dried the soil the most to persist for the longest. The predictive value of this relationship is investigated further in Figure 6 (b) which shows the receiver operating characteristic (ROC) of a binary classifier (drought continues / drought ends) which takes binned soil moisture deciles as input. Labelling the outputs as positive $p$ (drought continues) or negative $n$ (drought ends), there are four possible outcomes from the inputs. If a prediction is $p$ and the actual value is also $p$, the outcome is true positive $(T P)$; if the actual value is $n$ the outcome is false positive $(F P)$. Conversely, a true negative $(T N)$ has occurred when both the prediction outcome and the actual value are $n$, and false negative $(F N)$ is when the prediction outcome is $n$ while the actual value is $p$. The ROC curve is constructed 
by plotting the false positive rate $(F P R=F P /(F P+T N))$ against the true positive rate $(T P R=T P /(T P+F N))$ for different values of the predictor variable (soil moisture deciles in this case). The area under the ROC curve indicates the skill of the classifier. A perfect classifier would have $T P R=1$ and $F P R=0$ for all choices of predictor threshold and the area under the curve would be unity. A classifier with no skill would have $T P R=F P R$ always and the area under the curve would be 0.5. Thus, with an area of 0.64 , the soil moisture quantile of the drought footprint at 3 months shows some skill at predicting likelihood of a drought continuing beyond 3 months. A bootstrap estimate of the $95 \%$ confidence interval puts the area between 0.52 and 0.76 . The perpendicular distance between the ROC curve and the 1:1 line is a measure of the sensitivity of the classifier. This suggests an optimal threshold of 0.4 for the soil moisture footprint quantile. Outcomes from this classifier are presented in Table 1 . The odds ratio for this contingency table is 6.0 which corresponds to a Fisher exact probability (of seeing a table as extreme as this by chance) of 0.008 which implies a highly significant degree of predictability of drought continuation / cessation from the antecedent soil moisture.

\subsection{European drought in a warmer climate}

The close agreement between the characteristics of the modelled and observed droughts provides us with confidence that under present day control conditions HiGEM is capable of emulating a realistic European drought climatology. This motivates consideration of how the modelled droughts may change in the face of increased global temperatures.

Summary statistics representative of the European droughts in the warmer model world were computed for $2^{\circ} \mathrm{C}$ and $4^{\circ} \mathrm{C}$ temperature rises. We find a shift toward events of increased volume (severity) which is driven by increases in both event duration and area. The changes seen at $2^{\circ} \mathrm{C}$ (not shown) are relatively modest and are not considered to be significant. However, the dramatic changes seen at $4^{\circ} \mathrm{C}$ (Figure 7) are highly significant. It is interesting to note that the event rate first increased (34 droughts from 30 years at $2^{\circ} \mathrm{C}$ ) and then fell back slightly (30 droughts from 30 years at $4^{\circ} \mathrm{C}$ ) this is likely to be the result of merger of several 
smaller droughts into larger composite events (as seen previously in Figure 5).

Geographically (not shown) there is tendency for the event centroids to become clustered about the centre of the study region. This is to be expected since, as an artefact of the event identification procedure, larger scale events are more likely to grow toward the centre of a bounded region. Deeper insight into the likely geographical shifts in the pattern of drought can be gained from maps of the trend in the seasonal values of the SPI which are provided in Figure 8. These indicate a general drying in the Mediterranean in both summer and winter and a general increase in precipitation over northern regions in the winter.

In response to increased concentrations of atmospheric $\mathrm{CO}_{2}$, the modelled droughts are found to increase in duration, area and severity. These changes can largely be understood, with reference to the soil moisture feedback discussed above (Section 3.2) by the geographical distribution of the changes in $\mathrm{SPI}_{3}$ expected under a warmer world shown in Figure 8. These suggest a strong summer drying about the Mediterranean which extends further north and west with increasing temperature. This pattern of precipitation change for Europe is well known (see e.g. Section 11.3.3.2 of the $4^{\text {th }}$ Assessment Report of the Intergovernmental Panel on Climate Change (2007)). Rowell \& Jones (2006) describe four mechanisms which might explain the pattern of summer drying:

(a) an earlier and more rapid decline in SM during spring, leading to lower SM in summer, and hence less convective rainfall.

(b) a larger land-sea contrast in lower tropospheric summer warming, leading to reduced relative humidity in air advected onto the continent, and so reduced rainfall.

(c) other large-scale atmospheric changes, including remotely forced circulation changes.

(d) a positive feedback mechanism in summer, whereby the reduced rainfall dries the soil further, so reducing convective activity further.

The importance of soil moisture - rainfall feedbacks (items (a) and (d)) has already been made clear. Turning our focus to item (b) the modelled change in 
relative humidity from control for temperature rises of $2^{\circ} \mathrm{C}$ and $4^{\circ} \mathrm{C}$ is shown in Figure 9 for summer and winter seasons. The progression and pattern of reduction in relative humidity clearly mirrors the summer drying seen in the values of $\mathrm{SPI}_{3}$. The importance of item (c) the role of change in the large scale circulation, seems less certain. The dominant mode of atmospheric variability over Europe in summer is a variation on the wintertime north Atlantic oscillation (NAO) referred to as the summer NAO (or SNAO) Folland et al. (2009). The SNAO projects strongly onto a NNW-SSE dipole of precipitation anomalies. Under positive SNAO conditions summer precipitation deficits can be expected across much of Great Britain and Scandinavia. A model based SNAO index was computed by standardising the JulyAugust mean sea level pressure difference between the UK and Iceland. The index is plotted for the control run (black) and for $2^{\circ} \mathrm{C}$ (light grey) and $4^{\circ} \mathrm{C}$ (dark grey) warmer climates in Figure 10. In the case of the warmer climates the index was standardised relative to the control. The results, in concordance with Folland et al. (2009), show a progressive shift toward a more positively phased index. However, we do not see a pattern of drying across northwest Europe beyond that attributable to the change in relative humidity. The reason for this is not clear but it should be noted that, whilst significant, the SNAO only accounts for around $25 \%$ of the variance in precipitation over the area of northwest Europe (and only then for JulyAugust). Thus, it is quite possible that the SNAO change signal is obscured by other sources of variability.

Seager et al. (2010) describe a method for the separation of changes in precipitation minus evapotranspiration $(P-E)$ into dynamic and thermodynamic components and apply this to a collection of 15 models participating in the Coupled Model Intercomparison Project phase 3 (CMIP3). Results from this separation for HiGEM for the April-September half year (not shown) are found to be in excellent agreement with the CMPI3 study. At the European scale, the reduction of summer $\mathrm{SPI}_{3}$ closely matches the pattern of reduced $P-E$. Figure 4 of Seager et al. (2010) shows this pattern to result from a complicated mixture of thermodynamic and circulation changes in roughly equal measure. Thus whilst difficult to isolate, changes in the large scale circulation are considered to be important contributory factors to 
the projected intensification of European droughts in a warmer world.

Whilst the focus of this paper is on drought, it worth noting that the $\mathrm{SPI}_{3}$ change maps for winter shown in Figures 8 (b) and (d) show projected increases in precipitation for latitudes north of $55^{\circ} \mathrm{N}$. Again, this pattern is a well known response to increased green house gas forcing (see e.g. Räisänen et al. (2004)). However, unlike the summer changes, these are not attributable to the changes in relative humidity shown in Figure 9. In this case the change is thought to be due to a projected poleward shift and intensification of the extratropical storm tracks (Yin 2005) which would tend to increase the amount of large-scale precipitation at high latitudes.

\section{Conclusions}

Here we have shown that a new high resolution climate model (HiGEM) is capable of generating realistic European droughts. Encouragingly, we find excellent agreement between model and observations even in the extreme tails of the distributions of drought severity, duration and extent. The model is found to be consistent with the hypothesis that large scale coherent European droughts form from the agglomeration of smaller $\left(\sim 10^{6} \mathrm{~km}^{2}, \sim 3\right.$ month duration) events. Analysis of the modelled soil moisture fields strongly suggest that once a drought is formed it is likely to persist. A given drought that has already lasted for 3 months is $50 \%$ more likely to continue if the soil moisture beneath the footprint to date is below $40 \%$ of normal.

Encouraged by the model's ability to replicate the present day climate we investigated how the character of European drought may be expect to change in the face of warmer world. We find that drought severity (in the volumetric sense of Lloyd-Hughes (2012)) increases with temperature. The increased severity is driven by increases in both duration and spatial extent. The main driver for these changes appears to be a thermally driven reduction to the land-sea contrast and consequent reduction in relative humidity. Changes in the large scale circulation are known to contribute strongly to the modelled changes in vertically integrated $P-E$, however,

the relationship between these and the modelled changes in pattern of large scale 
European drought remain unclear.

Drought is one of the world's most dangerous weather related perils, here we have considered only Europe, it is important that the present analysis is extended globally.

Acknowledgements

Benjamin Lloyd-Hughes thanks Deloitte for supporting the Deloitte-Walker Institute Research Fellowship at the University of Reading. HiGEM was developed from the Met Office Hadley Centre Model by the UK High-Resolution Modelling (HiGEM) Project and the UK Japan Climate Collaboration (UJCC). HiGEM is supported by a NERC High Resolution Climate Modelling Grant (R8/H12/123). UJCC is supported by the Foreign and Commonwealth Office Global Opportunities Fund, and jointly funded by NERC and the DEFRA-MoD Integrated Climate Programme (GA01101, CBC/2B/0417-Annex C5). Model integrations were performed using the Japanese Earth Simulator supercomputer, supported by JAMSTEC. 


\section{References}

Barry RG, Chorley RJ. 2003. Atmosphere, weather 8 climate. Routledge, 8th edition.

Betts AK, Ball JH, Beljaars ACM, Miller MJ, Viterbo PA. 1996. The land surfaceatmosphere interaction: A review based on observational and global modeling perspectives. Journal of Geophysical Research. 101(D3):7209-7225.

Blackburn M, Methven J, Roberts N. 2008. Large-scale context for the UK floods in summer 2007. Weather. 63(9):280-288.

Catto JL, Shaffrey LC, Hodges KI. 2010. Can climate models capture the structure of extratropical cyclones? Journal of Climate. 23:1621-1635.

EC. 2007. Communication from the Commission to the European Parliament and the Council - addressing the challenge of water scarcity and droughts in the European Union. Technical report, European Commission.

Fennessy MJ, Shukla J. 1999. Impact of soil wetness on seasonal atmospheric prediction. Journal of Climate. 12:3167-3180.

Ferranti L, Viterbo P. 2006. The European summer of 2003: Sensitivity to soil water initial conditions. Journal of Climate. 19(15):3659-3680.

Fischer EM, Seneviratne SI, Vidale PL, Lüthi D, Schär C. 2007. Soil moistureatmosphere interactions during the 2003 European summer heat wave. Journal of Climate. 20(20):5081-5099.

Folland CK, Knight J, Linderholm HW, Fereday D, Ineson S, Hurrell JW. 2009. The summer north Atlantic oscillation: Past, present, and future. Journal of Climate. 22(5):1082-1103.

Guha-Sapir D, Hargitt D, Hoyois P. 2004. Thirty years of natural disasters 19742003: The numbers. Technical report, Presses Universitaires de Louvain, LouvainLa-Neuve.

Heim RR. 2002. A review of twentieth-century drought indices used in the United States. Bulletin of the American Meteorological Society. 83(8):1149-1165.

Intergovernmental Panel on Climate Change. 2007. Fourth Assessment Report: Climate Change 200\%: The AR4 Synthesis Report. Geneva: IPCC.

Jones PW. 1998. A user's guide for SCRIP: A Spherical Coordinate Remapping and Interpolation Package. Technical report, Theoretical Division, Los Alamos National Laboratory.

Kanamitsu M, Lu CH, Schemm J, Ebisuzaki W. 2003. The predictability of soil moisture and near-surface temperature in hindcasts of the ncep seasonal forecast model. Journal of Climate. 16(3):510-521.

Lloyd-Hughes B. 2012. A spatio-temporal structure based approach to drought characterisation. International Journal of Climatology. 32:406-418.

Lloyd-Hughes B, Hannaford J, Parry S, Keef C, Prudhomme C, Rees G. 2009. UK 
and European drought catalogue. Technical report, UK Environment Agency.

Martin GM, Ringer MA, Pope VD, Jones A, Dearden C, Hinton TJ. 2006. The Physical Properties of the Atmosphere in the New Hadley Centre Global Environmental Model (HadGEM1). Part I: Model Description and Global Climatology. Journal of Climate. 19(7):1274-1301.

McKee TB, Doesken NJ, Kleist J. 1995. Drought monitoring with multiple time scales. Ninth Conference on Applied Climatology. 233-236.

Mitchell TD, Jones PD. 2005. An improved method of constructing a database of monthly climate observations and associated high-resolution grids. International Journal of Climatology. 25(6):693-712.

Pal JS, Eltahir EAB. 2003. A feedback mechanism between soil-moisture distribution and storm tracks. Quarterly Journal of the Royal Meteorological Society. 129(592):2279-2297.

Peakcock JA. 1983. Two-dimensional goodness-of-fit testing in astronomy. Monthly Notices of the Royal Astronomical Society. 202:615-627.

Räisänen J, Hansson U, Ullerstig A, Döscher R, Graham L, Jones C, Meier H, Samuelsson P, Willén U. 2004. European climate in the late twenty-first century: regional simulations with two driving global models and two forcing scenarios. Climate Dynamics. 22:13-31.

Rowell D, Jones R. 2006. Causes and uncertainty of future summer drying over Europe. Climate Dynamics. 27(2):281-299.

Schär C, Lthi D, Beyerle U, Heise E. 1999. The soil-precipitation feedback: A process study with a regional climate model. Journal of Climate. 12(3):722-741.

Seager R, Naik N, Vecchi GA. 2010. Thermodynamic and dynamic mechanisms for large-scale changes in the hydrological cycle in response to global warming. Journal of Climate. 23(17):4651-4668.

Shaffrey LC, Stevens I, Norton WA, Roberts MJ, Vidale PL, Harle JD, Jrrar A, Stevens DP, Woodage MJ, Demory ME, Donners J, Clark DB, Clayton A, Cole JW, Wilson SS, Connolley WM, Davies TM, Iwi AM, Johns TC, King JC, New AL, Slingo JM, Slingo A, Steenman-Clark L, Martin GM. 2009. U.K. HiGEM: The New U.K. High-Resolution Global Environment Model - Model Description and Basic Evaluation. Journal of Climate. 22(8):1861-1896.

Sheffield J, Andreadis KM, Wood EF, Lettenmaier DP. 2009. Global and continental drought in the second half of the twentieth century: Severity-area-duration analysis and temporal variability of large-scale events. Journal of Climate. 22(8):19621981.

Smakhtin VU, Schipper ELF. 2008. Droughts: The impact of semantics and perceptions. Water Policy. 10(2):131-143.

Szalai S, Szinell C. 2000. Comparison of two drought indices for drought monitoring in Hungary - a case study. In JV Vogt, F Somma, editors, Drought and Drought Mitigation in Europe, 161-166. Kluwer: Dordrecht. 325pp. 
Wood AW, Maurer EP, Kumar A, Lettenmaier DP. 2002. Long-range experimental hydrologic forecasting for the eastern united states. Journal of Geophysical Research. 107(D20):4429-4444.

Yin JH. 2005. A consistent poleward shift of the storm tracks in simulations of 21st century climate. Geophysical Research Letters. 32(18):18701-18705. 
Table 1: Contingency table for the prediction of droughts continuing beyond 3 months durations from the quantile of the drought footprint at 3 months.

\begin{tabular}{l|c|r} 
& Duration $\leq 3$ months & Duration $>3$ months \\
\hline SM quantile $<0.4$ & 34 & 22 \\
\hline SM quantile $\geq 0.4$ & 3 & 9
\end{tabular}


(a)

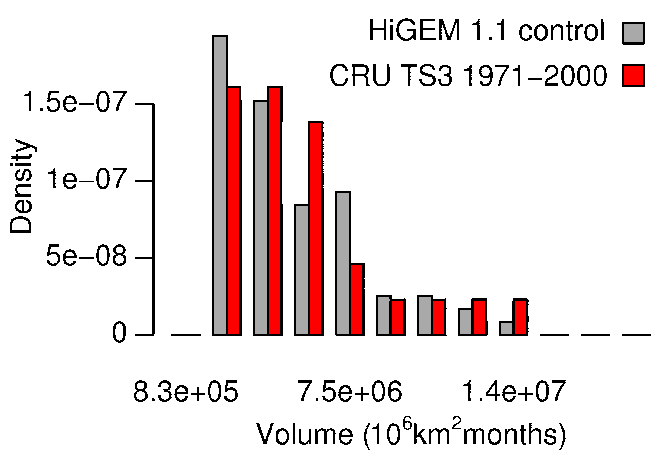

(c)

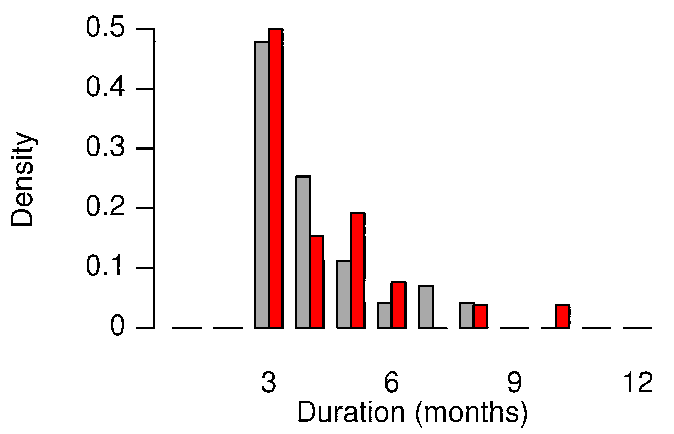

(e)

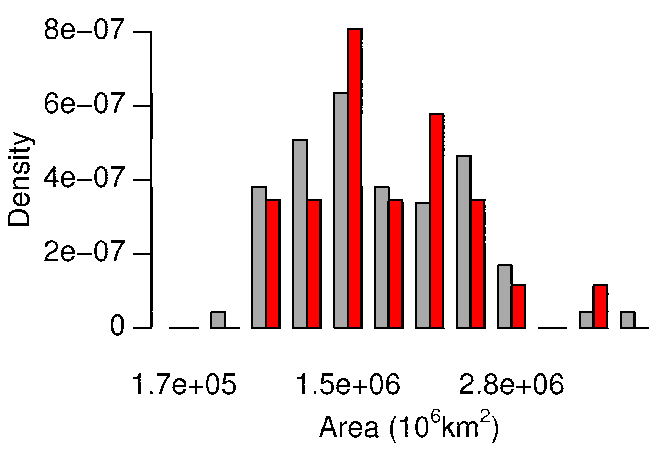

(b)

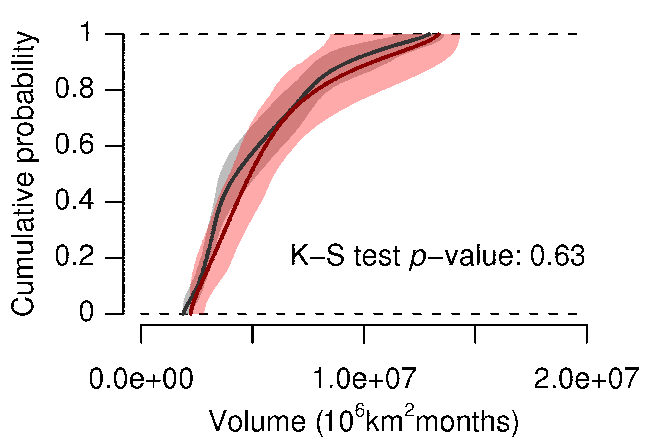

(d)

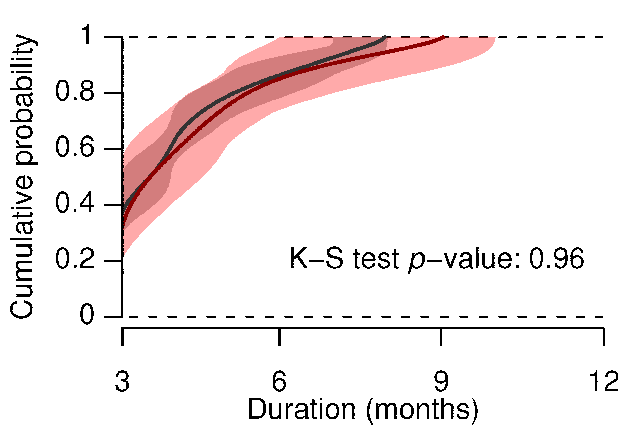

(f)

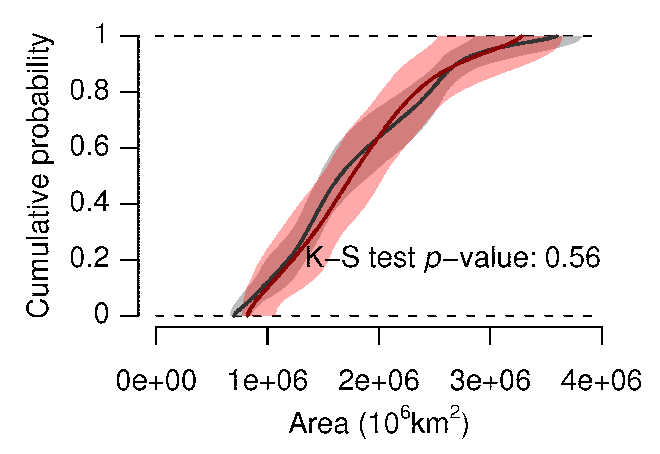

Figure 1: Summary statistics representative of structural elements of the drought events extracted from the HiGEM control run (black) and CRU observations (red). Panel (a) shows the probability density and (b) the cumulative probability for events of a particular volume (severity). Panels (c) to (f) show similar for event duration and maximum areal extent respectively. The shading shown in the cumulative plots represents the $90 \%$ interval estimated from 10,000 bootstrapped replicates of the curves. 


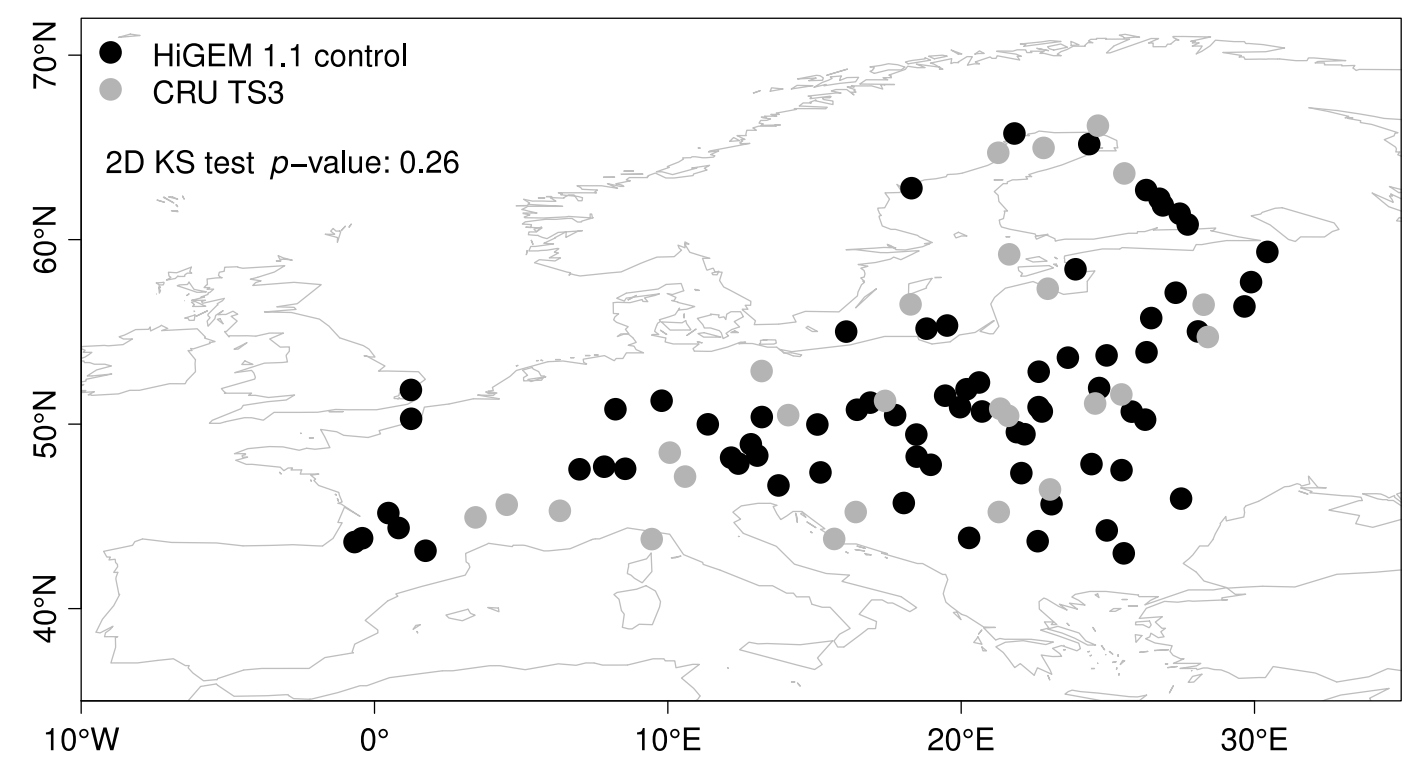

Figure 2: Geographical distribution of the event centroids from the HiGEM control run (black) and CRU TS3 (grey). 
(a)

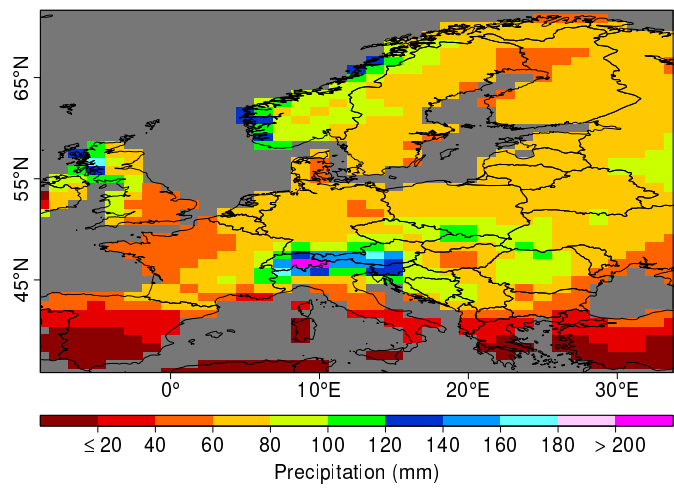

(c)

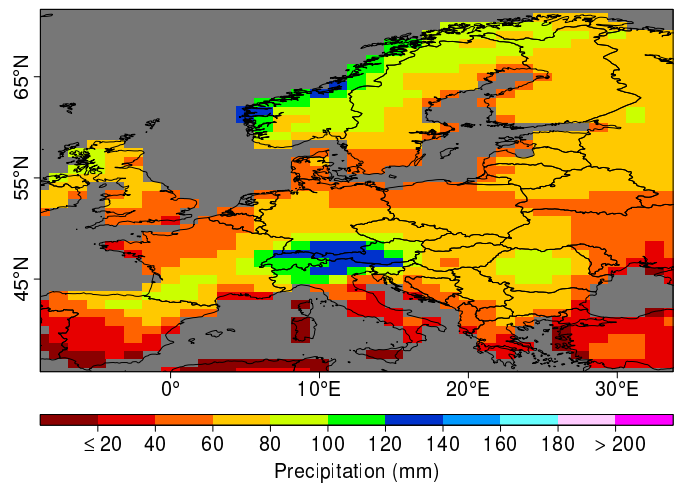

(b)

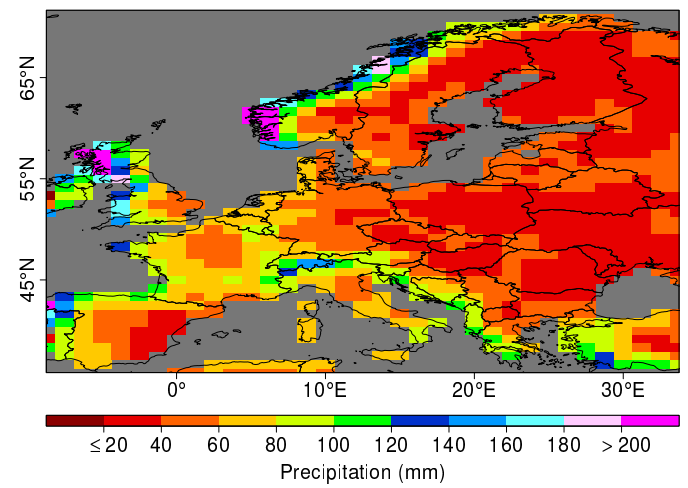

(d)

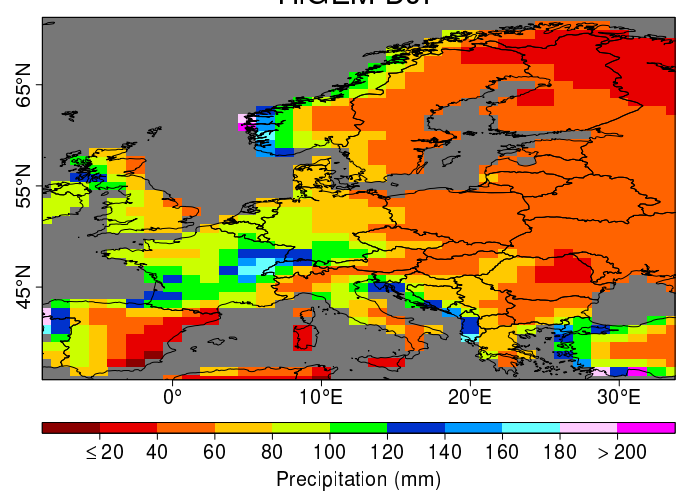

Figure 3: Grid cell comparison of the raw seasonal precipitation totals from the HiGEM control run with CRU TS3 observations. 
(a)

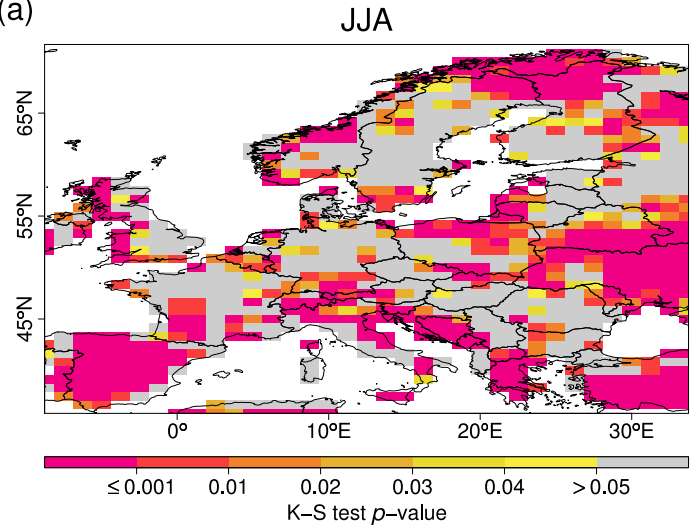

(c)

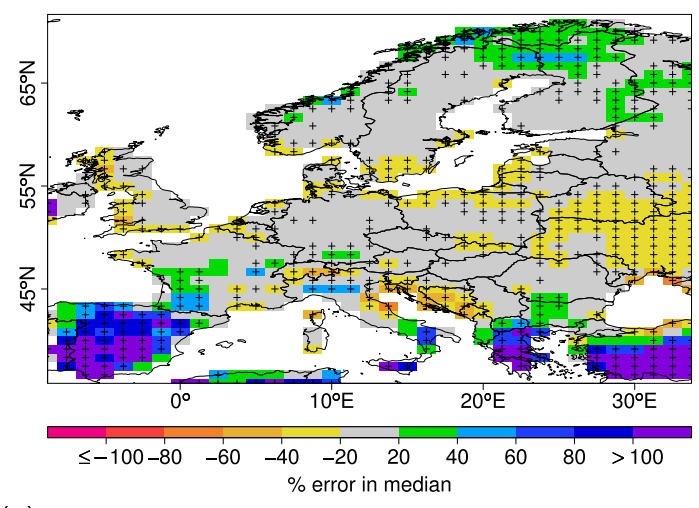

(e)

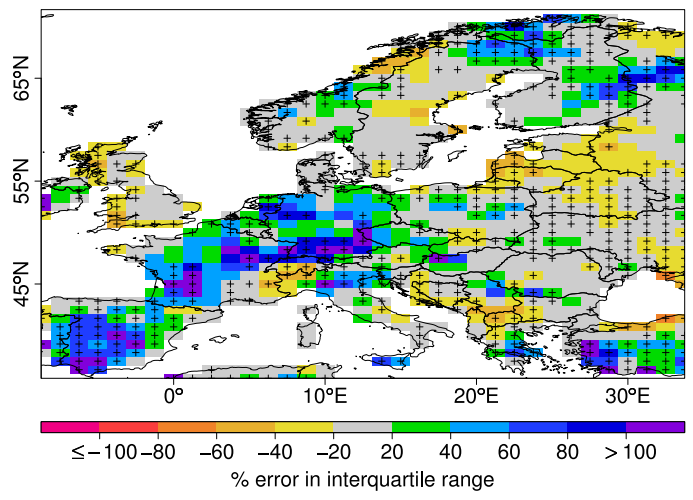

(b)

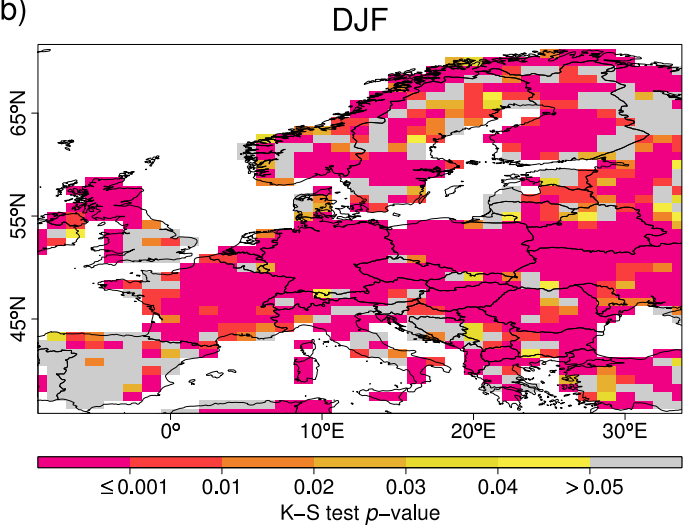

(d)

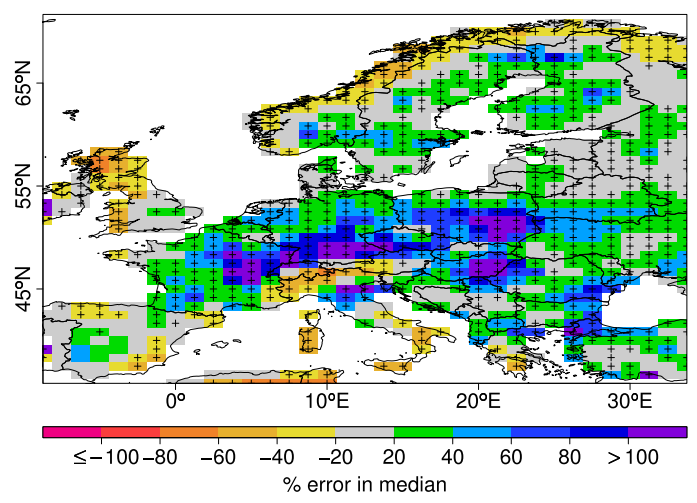

(f)

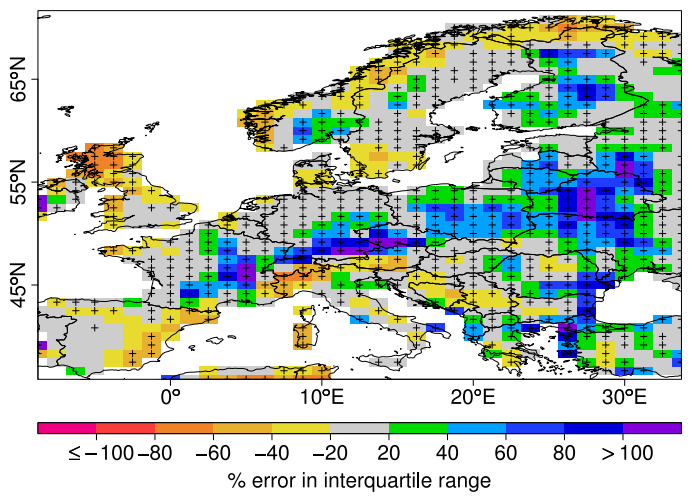

Figure 4: Grid cell comparison of the distributions of seasonal precipitation from the HiGEM control run with CRU observations. Panels (a) and (b) show the significance of the dissimilarity between the distributions as measured by the KolmogorovSmirnoff test for summer and winter respectively. Percentage errors in the medians are shown panels (c) and (d). Percentage errors in the inter-quartile range are shown in panels (e) and (f). Cells failing the KS-test with a $p$-value $<0.05$ are marked with a cross. 
(a)

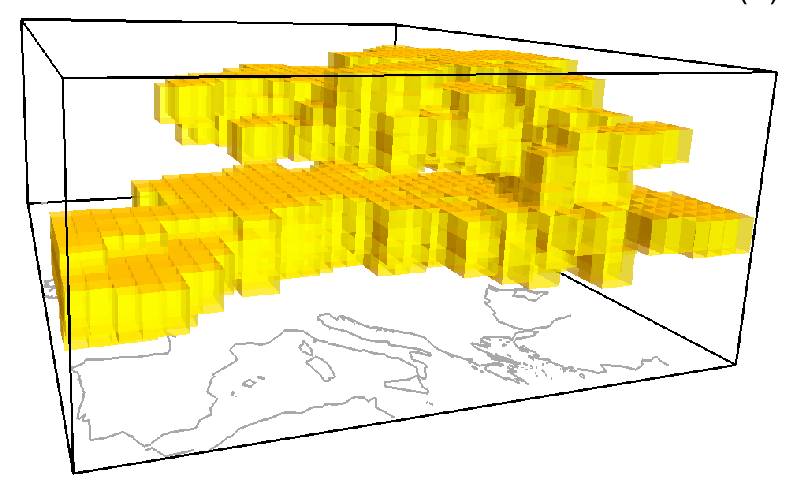

(c)

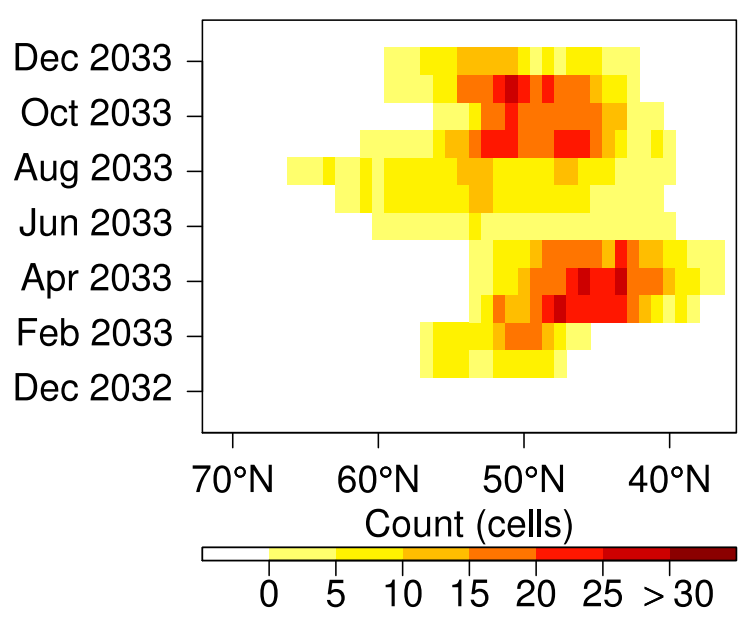

(b)

(d)
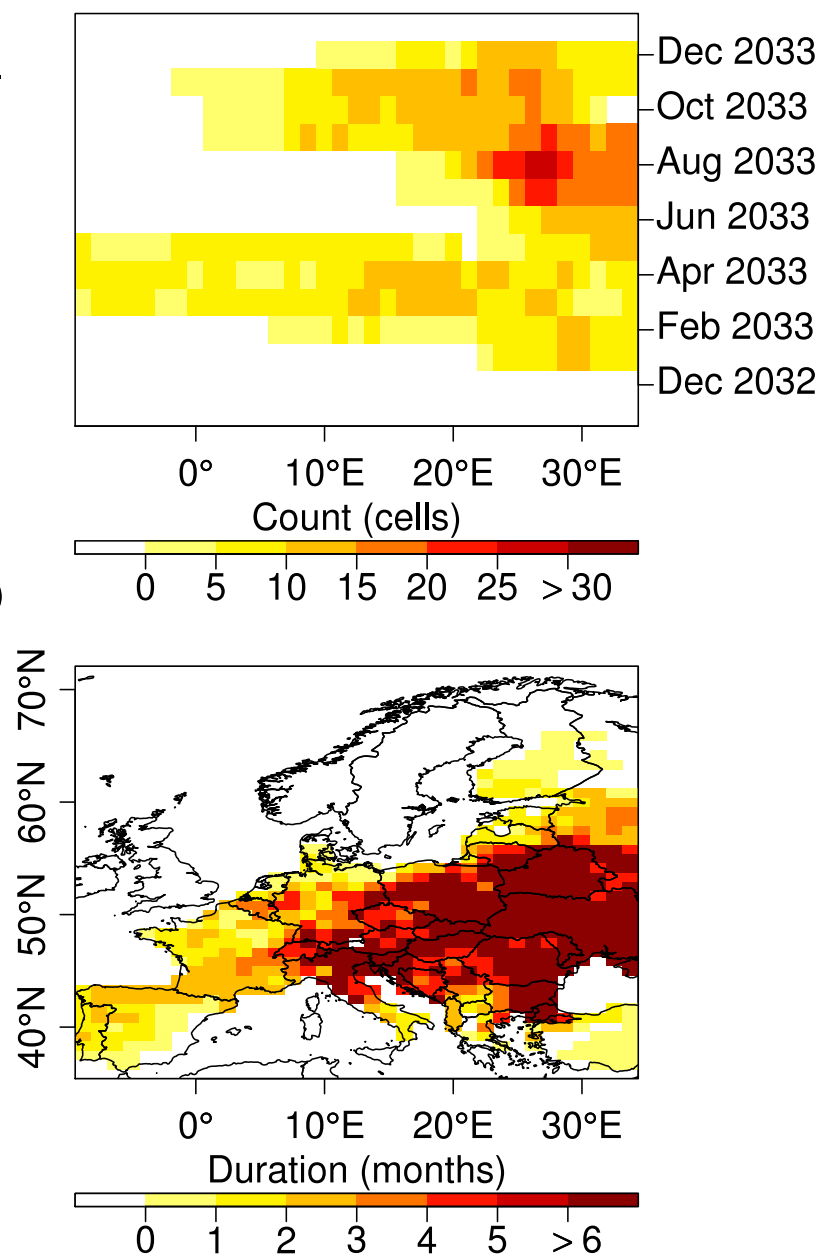

Figure 5: (a) Isometric view of a large scale drought extracted from the control run. (b) Hovmöller type plot of the number of grid cells in drought counted north-south through time. (c) East-west Hovmöller. (d) The view from above shows the drought severity and maximum spatial extent. 
(a)

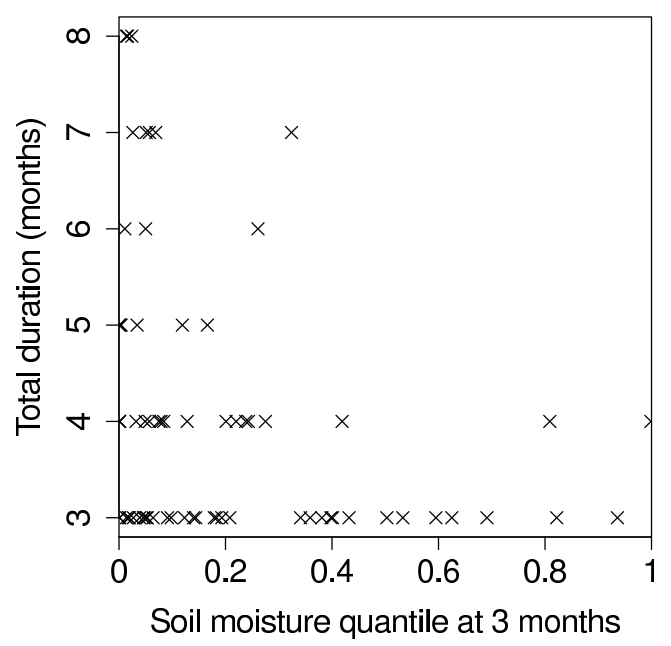

(b)

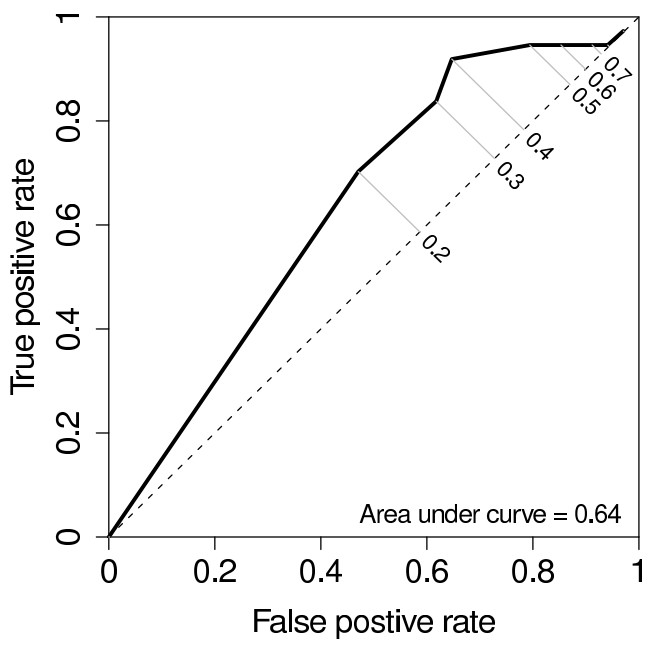

Figure 6: (a) Relationship between drought duration and the soil moisture level beneath its footprint at time three months. (b) Receiver operating characteristic (ROC) of a binary classifier (drought continues / drought ends) which takes binned soil moisture quantiles as input (diagonal labels). 
(a)

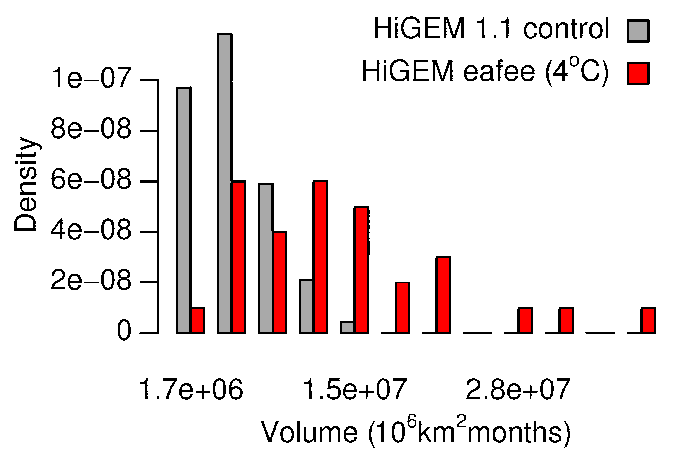

(c)

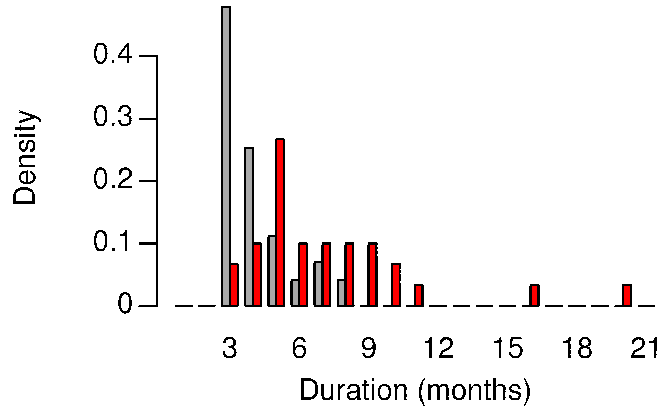

(e)

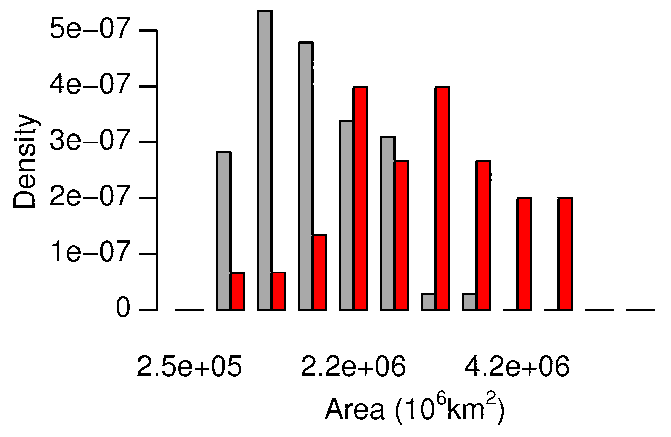

(b)

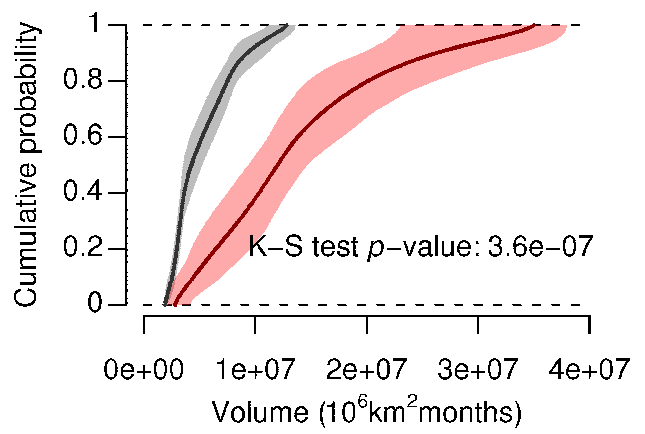

(d)

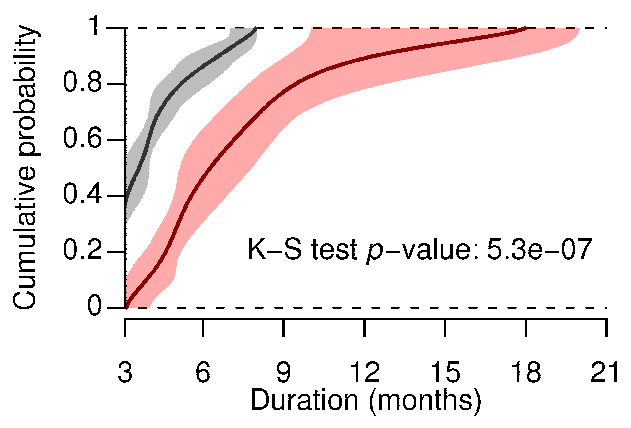

(f)

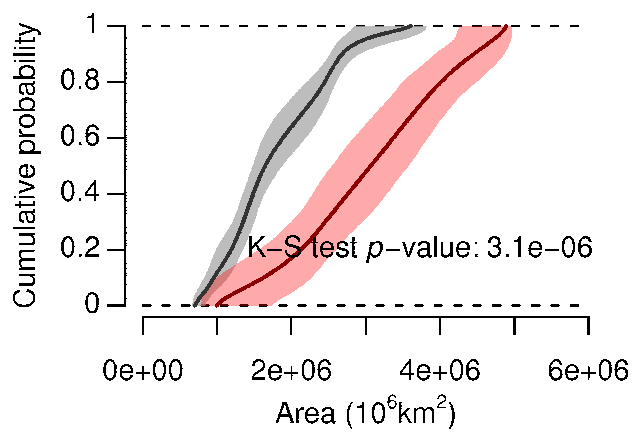

Figure 7: As Figure 1 but comparing modelled droughts representative of $4^{\circ} \mathrm{C}$ warmer world against the model control. 
(a)

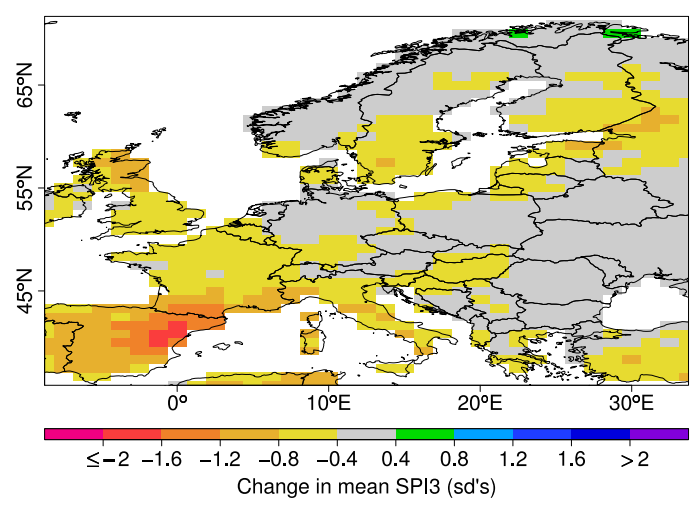

(c)

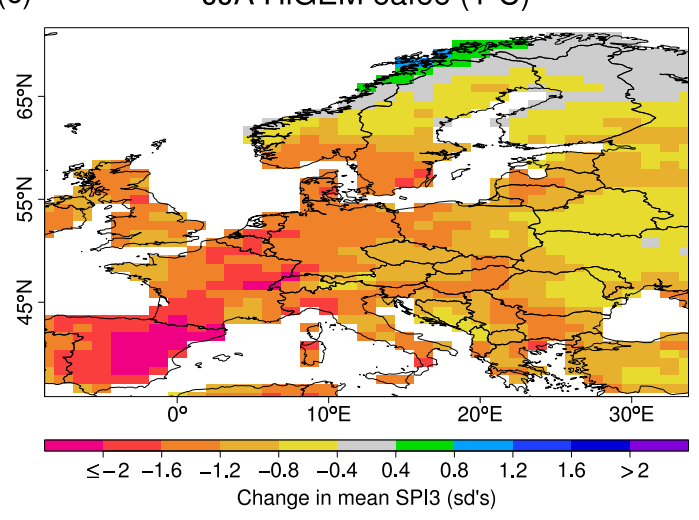

(b)

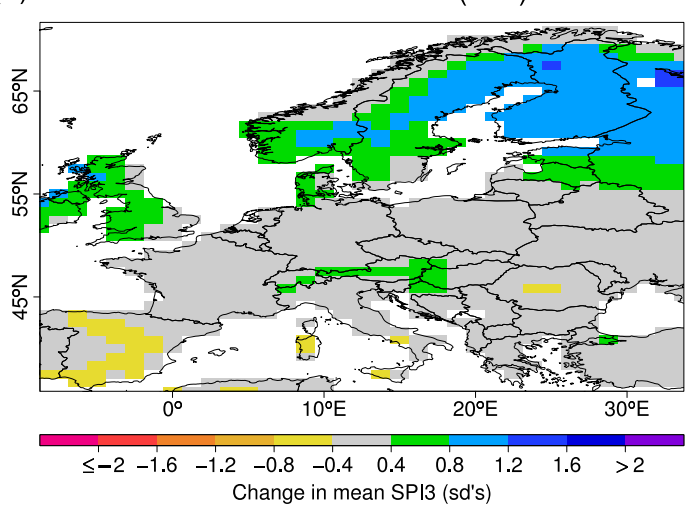

(d)

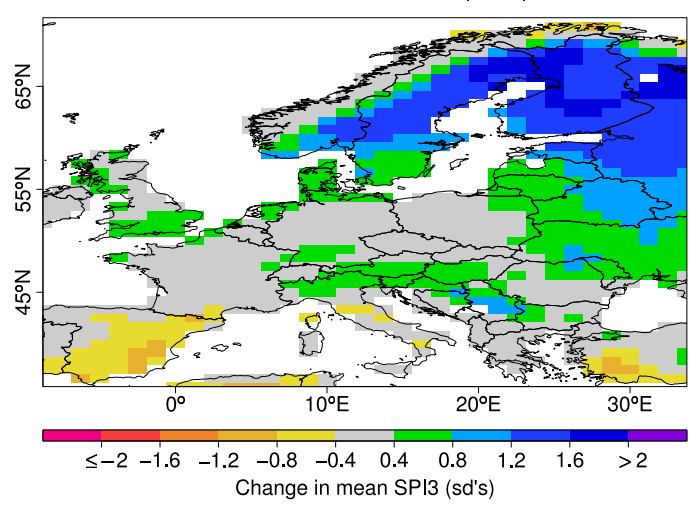

Figure 8: Changes in the seasonal values of the $\mathrm{SPI}_{3}$ (a) summer and (b) winter for a world $2^{\circ} \mathrm{C}$ warmer than the control. (c) and (d) similar but for a $4^{\circ} \mathrm{C}$ increase. 
(a)

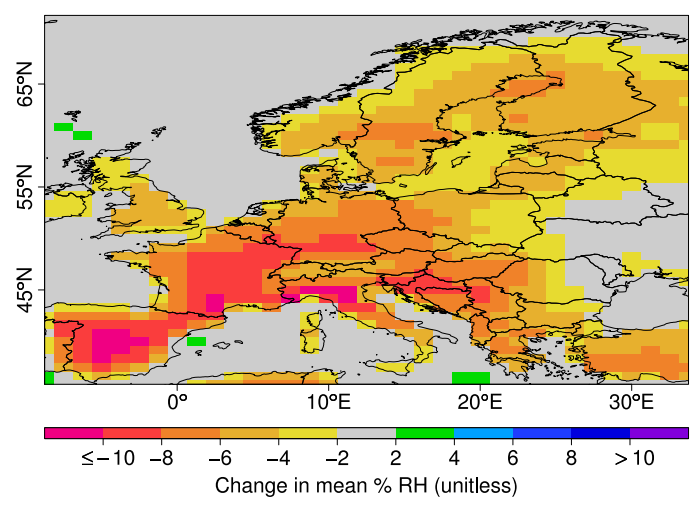

(c)

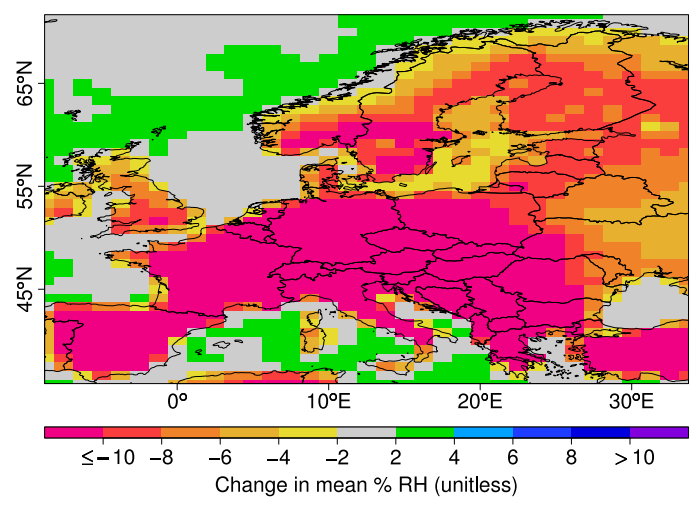

(b)

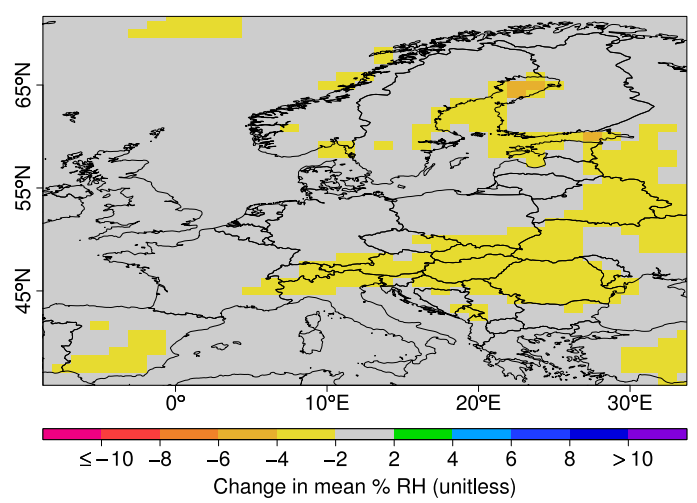

(d)

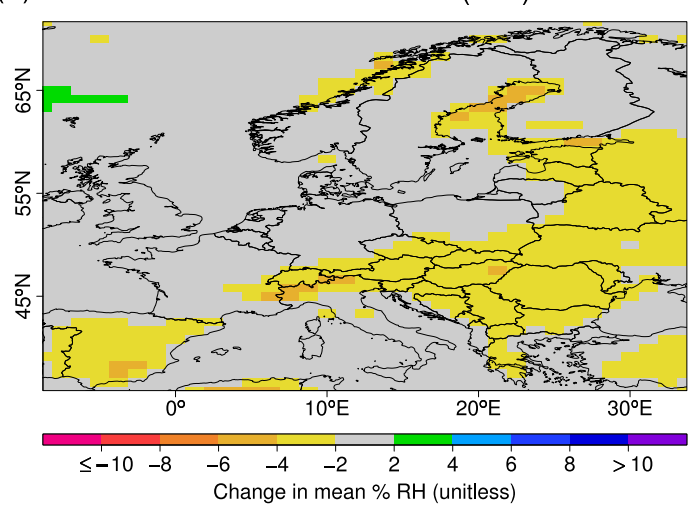

Figure 9: Changes in the seasonal mean relative humidity in (a) summer and (b) winter for a world $2^{\circ} \mathrm{C}$ warmer than the control. (c) and (d) similar but for a $4^{\circ} \mathrm{C}$ increase. 


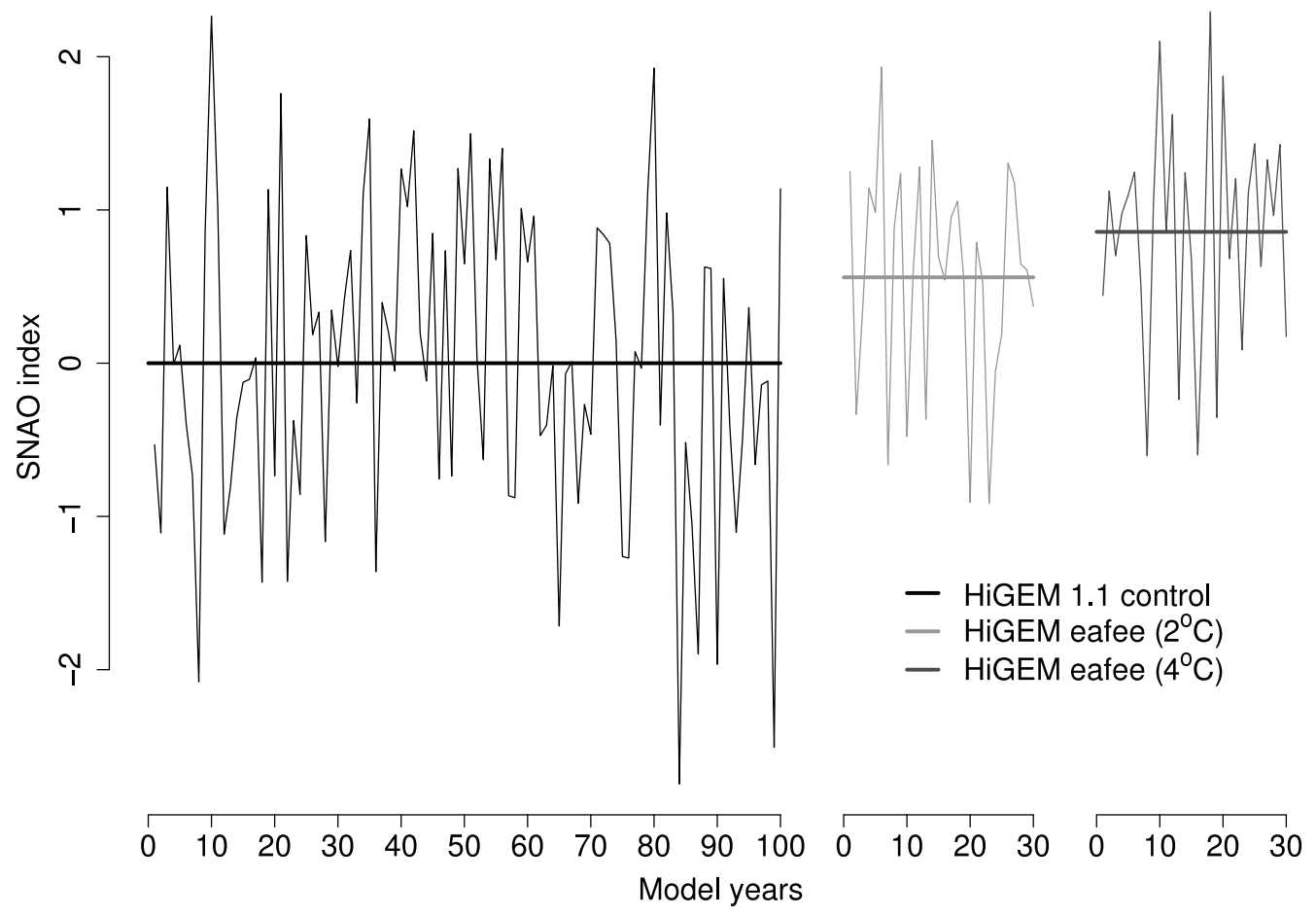

Figure 10: SNAO for the control (black), for a $2^{\circ} \mathrm{C}$ warmer world (light grey) and a $4^{\circ} \mathrm{C}$ increase (dark grey). The horizontal bold lines indicate mean values. 